\title{
Student's Mental Wellbeing in the Current Normal
}

\author{
Adelaine Gayle S. Delfin; Ahlexa Jane M. Molabola; Arrianni Grace S. Gozo; \\ Sharmaine O. Sim; Mary Claire O. Suson
}

adelainegayle@gmail.com; Lexamolabola@gmail.com; blinkee605@gmail.com; maryclairesuson7@gmail.com; sharmainesim01@gmail.com

P. Paterno Street, Leyte Normal University, Tacloban City, Philippines 6500

\begin{abstract}
This research aims to find out the concerns and challenges that most Senior Highschool students who are learning in Tacloban City are encountering during the outbreak of the Covid-19 virus. The researchers also aim to discover how these challenges affect the mental health of these Senior Highschool students, and how they cope with these challenges. The researchers have chosen this topic because of the new challenges brought by the Covid-19 virus, which includes the new normal that everyone is going through, especially students who have struggles learning in this new normal. The researchers have researched and analyzed topics related to students, mental health, and living in this new normal. The researchers used survey questionnaires and distributed them to a certain number of Senior Highschool students who are studying in school in Tacloban City. After data gathering, the researchers have carefully analyzed and understood the results of their survey by grouping the common concerns the Senior Highschool students have, how these concerns affect them, and how they handle these concerns.

It is shown that this new learning normal has affected the Senior Highschool students, physically, mentally, and academically. Most of the challenges that students have encountered are lack of devices, slow internet connection, having difficulty adjusting to the new normal, and time management with the number of tasks they have. Because of these, the students struggle to catch up with their academics, lose motivation, and endanger their mental wellbeing. Most of these students handle these struggles by having coping mechanisms, such as better time management, finding alternatives, and seeking support. While we're going through a pandemic, there are a lot of new concerns and challenges that we are yet to discover and this research aims to discuss a few of those new concerns.
\end{abstract}

\section{Introduction}

The new coronavirus (COVID - 19) outbreak has spread over the world, wreaking havoc on people's lives. The Philippines is one of countries afflicted, having documented the first fatality outside of China. This crisis created the current or new normal forcing the country to adopt lockdown strategies with potential concerns on day to day life, mental and physical health of the people, including students. The unprecedented COVID - 19 pandemic is now a global concern affecting the quality of life of the people. Because students make up such a large part of a country's population, their mental health should be a primary priority during this pandemic. The prevalence of several risk factors of students' mental health sufferings (i.e., depression, anxiety and stress) are among those that invite primal attention. 
This pandemic is seen to carry with its high potential to affect students physically, academically, financially, and psychologically. Schools across the country have quickly transitioned from in-person to online learning delivery of information in a short amount of time. Students have undergone significant changes throughout that time, as they have been pushed to leave campuses and adapt to new learning environments, including on-line learning platforms. Some of these students may have encountered innumerable difficulties with access to computers and interact at home due to financial disadvantages. Additional challenges may include teachers who are caught unprepared to toe the line of being not used to the practice, their way of dealing with students could add frustrating experiences to them. Other issues may include concerns about their health, the health of family members, and financial concerns, particularly for people who rely on jobs in industries that have been severely hit by lengthy closures.

With all of these growing problems, pupils' mental health will be severely impacted. Mental health issues can surely out space students' academic success and social interactions could negate their future careers and personal opportunities. This current normal could impair the mental wellbeing of students.

Students therefore are at high risk of psychological distress especially in cases of traumatic events that they may encounter. The evolution of this pandemic is quite uncertain. Nobody knows as to when the onslaught of this crisis will end. The continued experience of students in this current may have long - term effects on the mental wellbeing of students. Therefore, this study is considered timely to determine the impact of this pandemic on the mental wellbeing of the students. Being able to identify the vulnerable groups, strategic plans and programs could be devised to assist and reduce the burden of possible psychological problems.

\subsection{Research Questions}

1. How do the students cope with the different situations?

2. What are the challenges that they encounter?

\subsection{Theoretical Framework}

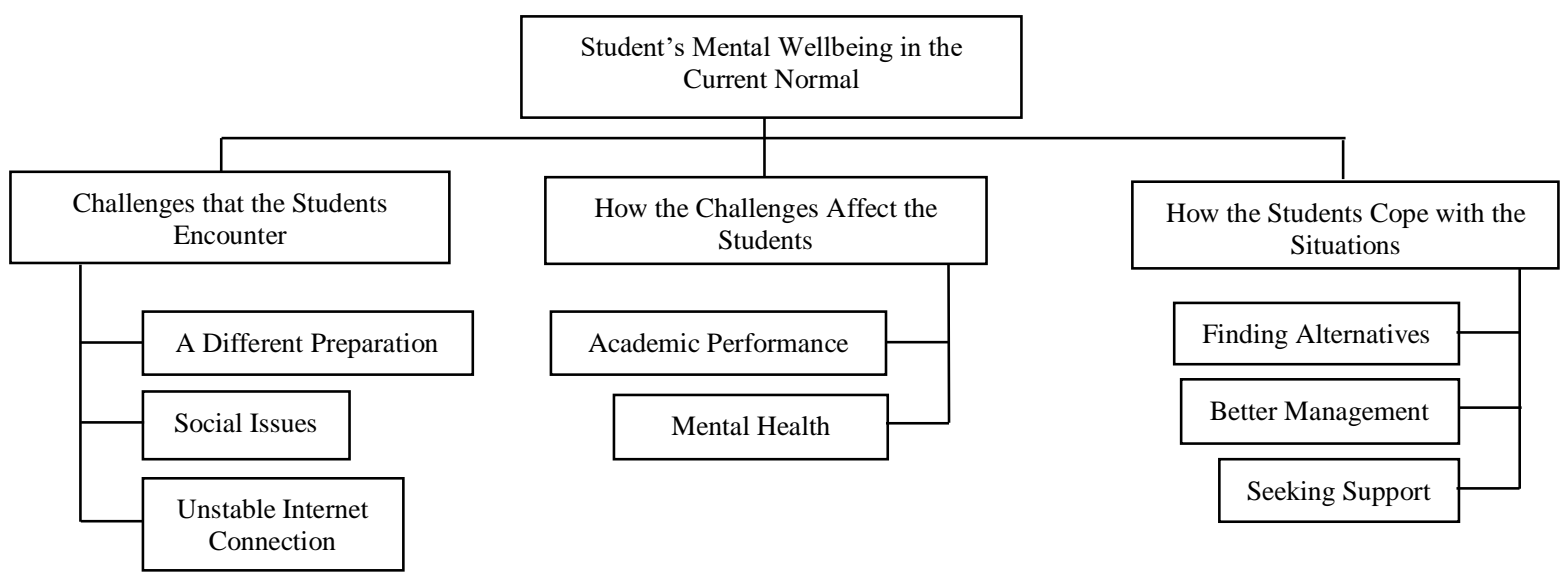

Figure 1. Framework of the Factors Relating to the Student's Mental Wellbeing in the Current Normal. 
In recent years there has been an increased interest in student mental wellbeing within higher education (Rajvinder Samra \&Mathijs Lucassen). The entire planet has been in a state of anarchy since the outbreak of a coronavirus illness (2019-nCoV) in December 2019. Isolation strategy with quarantine is a useful model in controlling transmission and rapid spread. As a result, people remained at home and disrupted their outside daily activities. It led to the closure of educational institutes, which is a source of many students to cope with numerous personal and familial issues (Muhammad Aqeel, Kanwar Hamza Shuja, Jaffar Abbas, Tasnim Rehna, Arash Ziapour). The diagram below shows the theoretical framework that is in relation with our research.

\section{Review of Related Literature}

The present COVID-19 pandemic has brought extraordinary challenges and has affected the educational sectors, and no one knows when it will end. Every country is presently implementing plans and procedures on how to contain the virus, and the infections are still continually rising. In the educational context, to sustain and provide quality education despite lockdown and community quarantine, the new normal should be taken into consideration in the planning and implementation of the "new normal educational policy". (Tria, 2020)

We know it is a very different and unsettling time for everyone as we transition to our 'new normal' and that these exceptional circumstances are a change for our educators, students and their families. However, change brings opportunities as well as challenges. (International School Partnership, 2020)

In response to these situations, educational leaders decided to adopt the new normal in education. At the basic education, the Department of Education (DepEd) will be implementing the Learning Continuity Plan (LCP). (Tria, 2020)

The Department of Education (DepEd), with its stakeholders and partners, has pushed for learning continuity and created various alternative learning modalities that go beyond the four walls of the classroom. (The Manila Times, 2020)

On the issue of holding virtual or online classes, Madam Secretary has suggested that the teaching methods and curriculum be updated with the emphasis on online teaching. [4] Here, we have a problem already. Not all students have ready access to the World Wide Web. Even teachers have limited access to it especially if the area they are in has slow to no connection at all. We know the Philippines has one of the very slow internet connections among ASEAN countries if not the slowest. (Guadalquiver, 2020)

If a student has a hard time adjusting to "the new normal," or is scared of the uncertainty in their future, they could begin to experience a high anxiety that will affect may aspects of their lives: their social connections, their physical health, and indeed, their performance in school. (UNESCO, 2020)

Mental health refers to cognitive, behavioural, and emotional well-being. It is all about how people think, feel, and behave. Mental health can affect daily living, relationships, and physical health. (Felman, 2020) Mental health includes our emotional, psychological, and social well-being. It affects how we think, feel, and act. It also helps determine how we handle stress, relate to others, and make choices. Mental health is important at every stage of life, from childhood and adolescence through adulthood. (U.S. Department of Health \& Human Services, 2020) 
Major depressive disorder and generalized anxiety disorder rates are more pronounced among low-income students; students of color; women and non-binary students; transgender students; gay or lesbian, bisexual, queer, questioning, asexual, and pansexual students; and, students who are caregivers. The prevalence of major depressive disorder and generalized anxiety disorder is higher among the undergraduate and graduate students who did not adapt well to remote instruction. (Chirikov, et al., 2020)

The articles the researchers have gathered have urged them to find out how the students cope with the "new normal", to find out what have caused these problems among students and how these problems affect them and their studies.

\section{Research Design and Methodology}

As a result of the pandemic, online learning is the current normal system of education. Some students are having difficulties with online learning and one of the most significant difficulties are mental health issues. In this study, we aim to investigate the mental state of senior high school students by conducting an assessment. The data gathered will highlight the impact of the pandemic on the mental health of senior high school students.

\subsection{Research Participants}

The research participants will be randomly chosen students from different schools in Tacloban City. The participants will be five students who are senior high school students who are learning through online learning. The research will only be limited to students who are studying in schools from Tacloban City and only senior high school students will be interviewed or surveyed.

\subsection{Data Gathering Procedure}

We conducted our survey questionnaire by using Google forms for the randomly selected students. For those who couldn't access the Google form, we sent them the questions via messenger.

1) Find students who are interested in participating in the research.

2) Ask consents from the interviewees before conducting the interview.

3) Let them answer the questionnaire prepared.

4) Ask the participants about their ideas and anything more they would like to emphasize about the situation.

5) Sort and examine the data collected from the participants.

\subsection{Data Analysis Method}

For this study, the descriptive research method will be utilized. In this method, it is possible that the study would give reflections to the readers about their personal wellbeing. Therefore, the researchers will conduct an online survey using questionnaires for the target students. They will also be taking an online test which is similar to The Depression, Anxiety and Stress Scale - 21 Items (DASS-21) which is a set of three self-report scales designed to measure the emotional states of depression, anxiety and stress. Each of the three DASS-21 scales contains 7 items, divided into subscales with similar content. This study will first review the articles related to the research being conducted in order to come up with questions and concerns that will be asked of the target students.

The purpose of this methodology is to understand the causes and the effects of the "new normal" in the field of learning among high school students in Tacloban City. We will also understand how students cope with the different situations they have encountered in the "new normal". 
To come up with the answers to our questions, we will be preparing questionnaires that will be given out to the target audience to make it easier to gather their basic information, which will be useful for the data. The researchers will then select five (5) high school students from randomly selected schools in Tacloban City. The research will only be limited to the high school students learning in the Tacloban Area.

The statements we have gathered from the target audience will be thoroughly understood and analysed in order to gather the data needed in order to answer the questions how and what are the causes, how it affects them, and how they cope with the situations they have encountered.

\section{Results and Discussion}

With the use of the survey questionnaire that was distributed, they were able to find the and gather the data needed for the study. After the researchers gathered the data they need, they have carefully analysed the data from their participants.

Table 1. Collected Data from the Questionnaires

\begin{tabular}{ccccc}
\hline Participant & Age & School & Grade Level & Strand \\
\hline 1 & 17 & Sagkahan National High School & 11 & HUMMS \\
2 & 18 & Liceo del Verbo Divino (LVD) & 11 & STEM \\
3 & 18 & Dr. V. Orestes Romualdez Educational Foundation & 11 & STEM \\
& & (DVOREF) - SHS & & GAS \\
4 & 17 & Asian Development Foundation College (ADFC) & 11 & HUMMS \\
5 & 17 & Leyte Normal University - Integrated Laboratory & 11 & School (LNU-ILS) \\
& & & & \\
\hline
\end{tabular}

Table 2. How the participants connect to the internet.

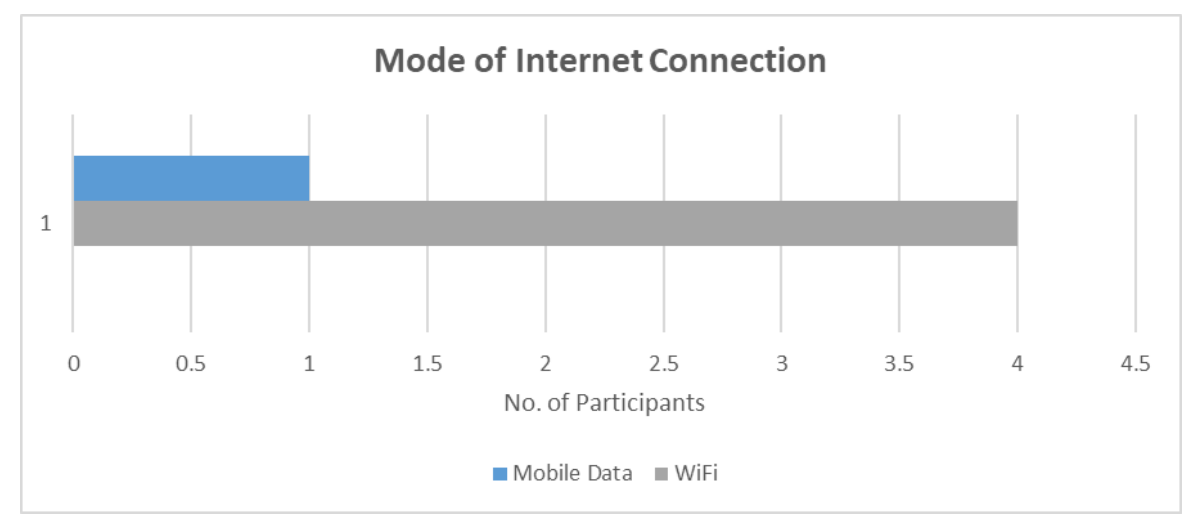

4 of our participants use Wi-Fi to connect to the internet, while 1 of our participants use Mobile Data to connect to the internet.

When it comes to the participant's internet stability, 4 of our participants sometimes have stable internet connection while 1 of our participants has no stable internet connection at all. This situation becomes a frequent problem among 4 of our participants while it rarely becomes a problem to 1 of our participants. 
Table 3. The available devices the participants use in online classes.

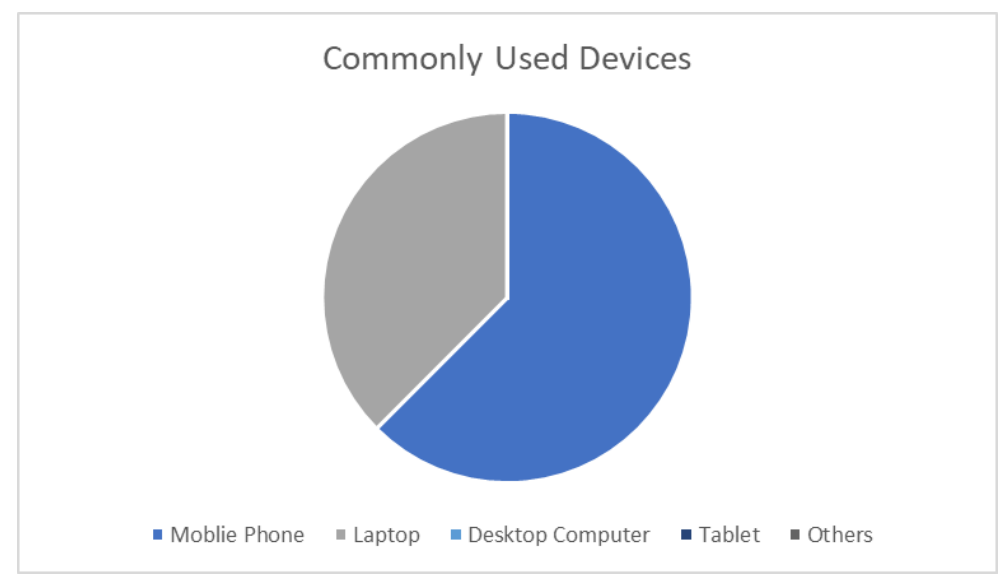

Among our participants, the most commonly used device for online classes was the Mobile Phone, the second commonly used was the laptop while none of our participants use other devices.

Lack of devices sometimes becomes a problem among 2 of our participants, it frequently becomes a problem among 2 of our other participants, while only 1 of our participants doesn't experience any problems at all during their online learning.

Table 4. Participant's Common Problems

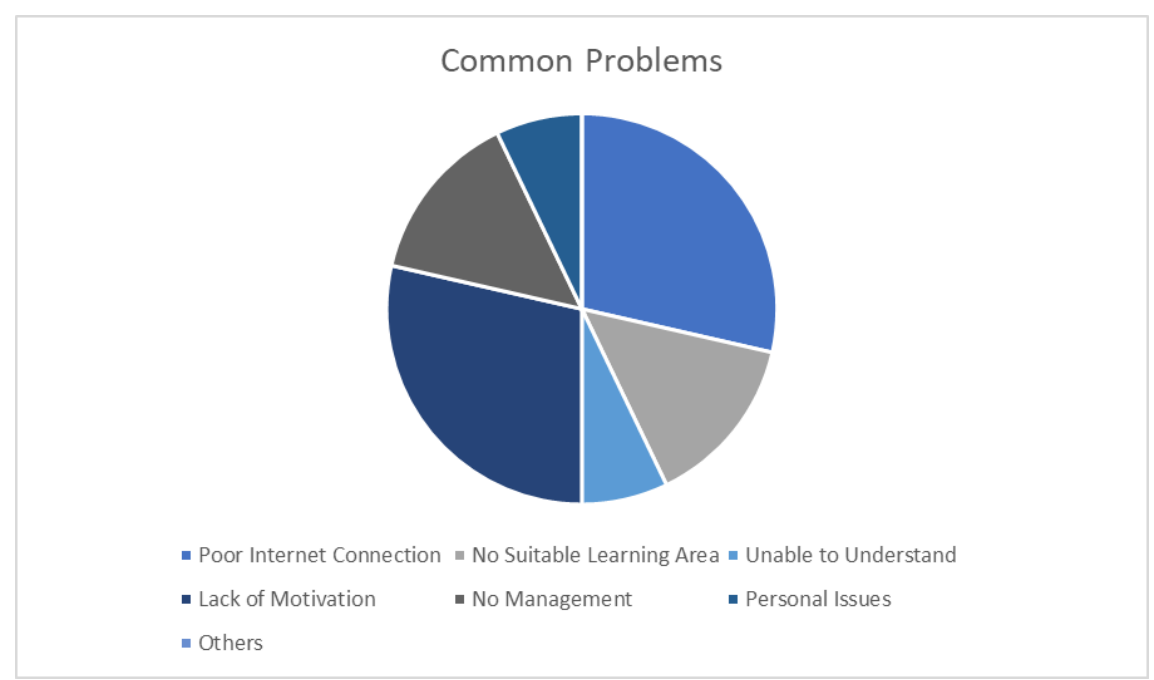

The common problems our participants experience is poor internet connection and lack of motivation. 
Table 5. How often do these problems affect your online learning?

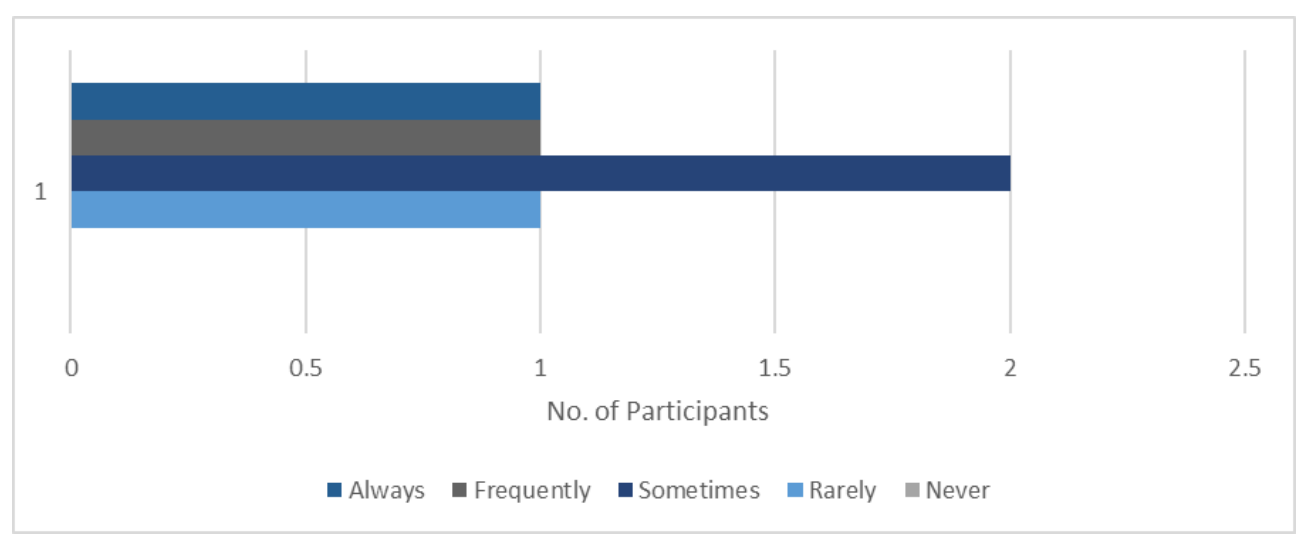

Table 6. Participant's Results in The Depression, Anxiety and Stress Scale - 21 Items (DASS-21) test.

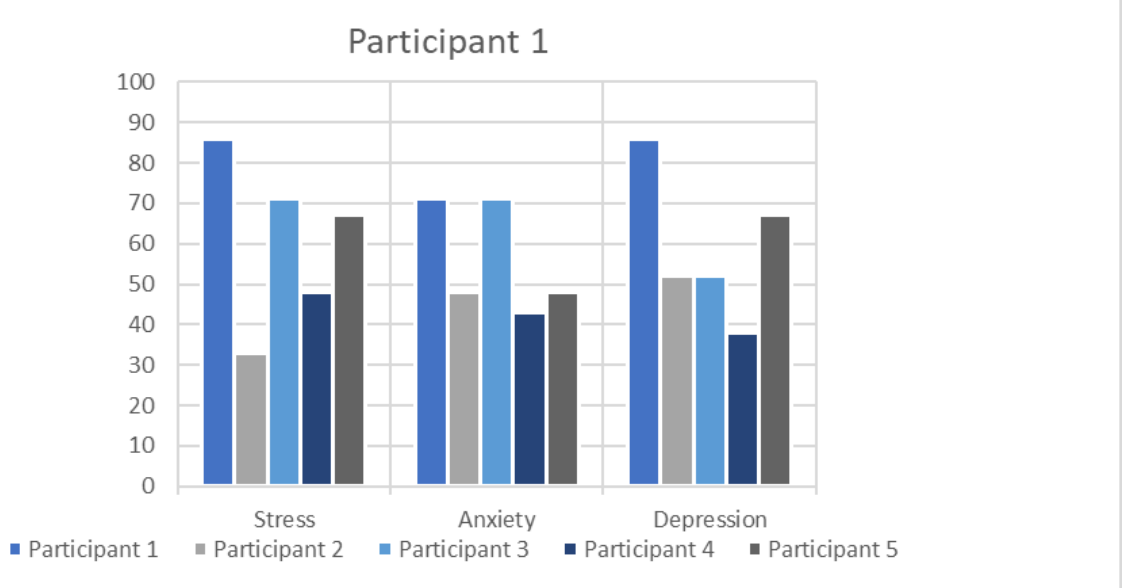

Among our participants, 4 of them feel frustration while 1 of them feel anxious when they encounter these problems. 
Table 5. How often do you experience the certain feeling?

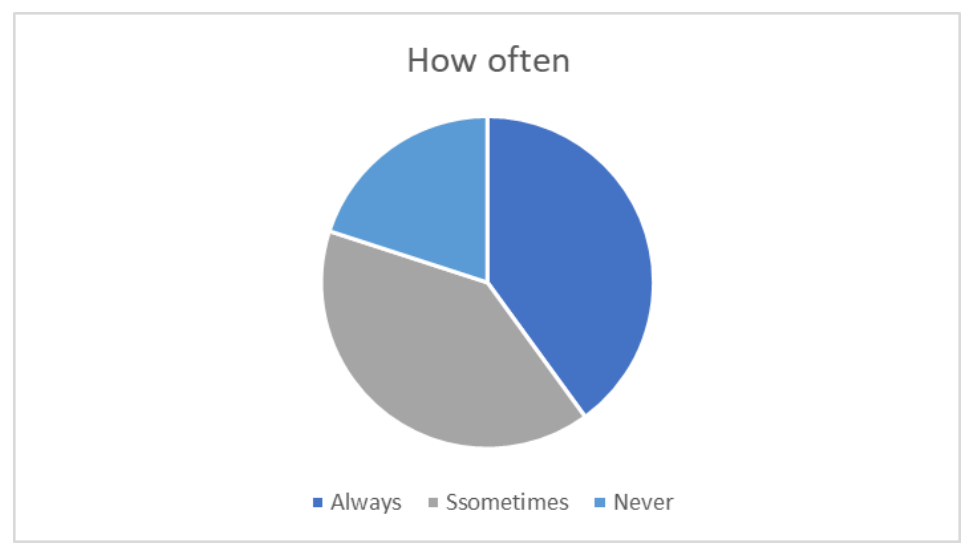

2 of our participants answered that they sometimes feel these emotions, 2 of them answered that they always feel these emotions while 1 of them stated that they never feel these emotions. We asked our participants if they think that online classes contributed to these results, 2 of them answered Yes, 2 of them answered Maybe, while 1 of them answered No.

Table 6. Participant's Common Coping Mechanisms

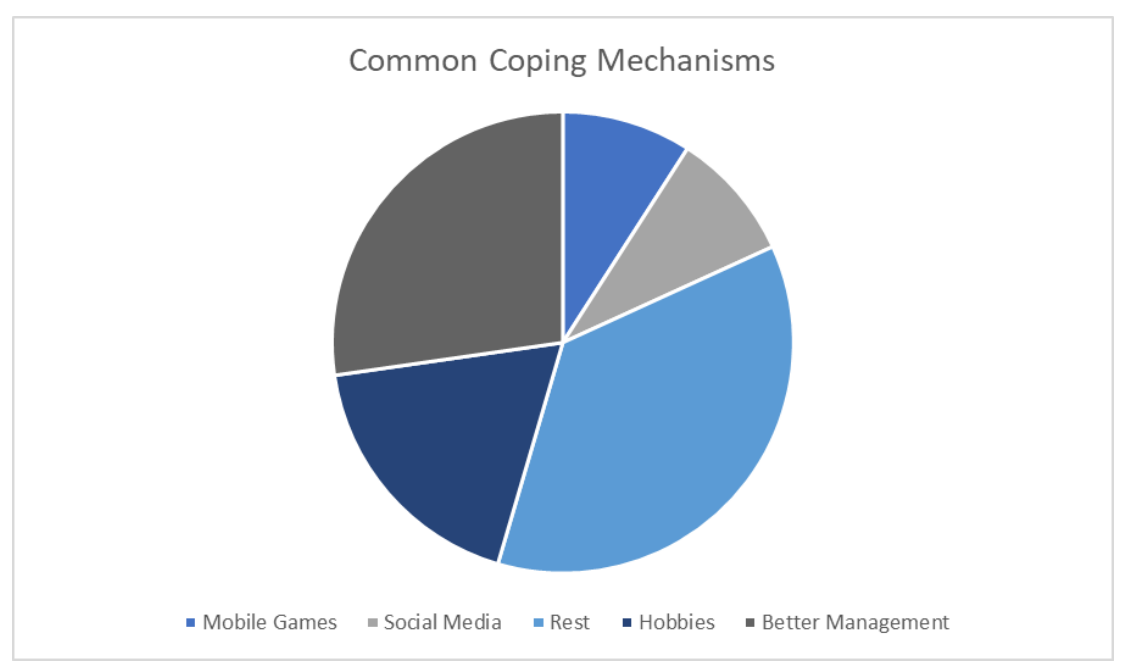

The participants prefer to rest as their coping mechanism, while the second most common coping mechanism is having a better management with their tasks and time.

The data that the researchers have gathered have given away many ideas that were a big part of the research. The researchers have found 3 (three) common problems that the participants have experienced in the new online learning, the researchers also found out that it affects the participants in 2 (two) common ways, and lastly, they have found 3 (three) ways of how the participants cope with the current situation and the problems they have experienced. The said variables are as follows; 


\section{Common problems the participants have experienced}

\section{Unstable Internet Connection}

All of the participants stated that they have unstable internet connections or are unable to connect to the internet which becomes a huge problem during their online classes.

"Having slow internet connection." (P4)

"The Wi-Fi internet is sometimes not stable" (P5)

\section{A Different Preparation}

There were a few participants who stated that they weren't prepared for the new online learning and there were some who stated that they are still struggling with the new set up in the new learning normal.

"Lack of gadgets such as laptop" (P1)

"Switching from traditional classroom and face to face training to computer-based training in a virtual classroom makes the learning experience entirely different for students." (P2)

"The Wi-Fi internet is sometimes not stable, also since we are just renting a house in Tacloban, going home to my real hometown and coming back here during weekdays can cause me some absences during classes." (P5)

\section{Social Issues}

One of our participants stated that they were having hard time communicating with their fellow school or classmates and as well as their teachers because of the barriers they encounter due in the new normal.

"In these trying times it is hard to have a good communication with them because of the barriers which affects the understanding on both sides." (P2)

\section{Common ways how the problems affect the participants}

\section{Academic Performance}

The participants stated that due to the challenges they have or are experiencing greatly impacts their academic performance wherein they have a hard time complying, catching up with the lessons, and have a hard time understanding the lessons being taught to them.

"It affects my academic performance." (P4)

"It hinders me from working on my school works immediately." (P3)

"The moment I absent at even one session, then the next time I join, I felt like a huge gap had already passed through me that I can't follow up and understand the lessons sometimes anymore." (P5)

\section{Mental Health}

The participants stated they the challenges they have experienced have greatly impacted their mental health. They have mental breakdowns, they are stressed and most of them lose motivation during their online learning.

"It affects my mental stability and thus I am often experiencing mental breakdowns and multiple suicide attempts." (P1) 
"Anxiety and depression have also been developed due to staying at home, by not feeling the ambiance of the school itself and also because of my sleeping disorder." (P2)

\section{Ways the participants cope with the challenges}

\section{Finding Alternatives}

One of the participants stated that they look for other ways in coping with the problem such as looking for other possible ways on how to solve the problems they have experienced during their online learning.

"As a learner, we need to find alternative ways to cope up having weak access of internet or we need to be initiatives in finding other ways, because if we want to learn we need to do our part as learners." (P2)

\section{Seeking Support}

One of the participants stated that, in times of difficulty, they ask for help among their friends or relatives. In times like these, it is natural to ask for help when things get overwhelming for people.

"I borrow laptop from my sister and ask for a friend's help if I don't have a load to be used in our online classes. I also ask guidance and strength from the Almighty, to keep my focus and to empower my optimism during these trying times." (P1)

\section{Better Management}

The rest of the participants stated that they find better ways and set up priorities and schedules that can help them adjust and focus. Example of these were better time management, setting priorities, and setting time for oneself.

"Do my school works when there is fast internet connection." (P3)

"Managing my time is the number one struggle in this situation. So, as much as possible I try to make a schedule so that I will be able to remember all the tasks and deadlines that are needed to be done." (P2)

"By making sure to attend classes by looking at some situations on either I can still attend. Also, by limiting myself to some other things that can cause these problems." (P5)

\section{Conclusion}

It is said that this pandemic is seen to carry with its high potential to affect students physically, academically, financially, and psychologically. In a short period of time schools across the country has rapidly switched from in - person to on - line learning delivery of content. With that brief period, students have dramatically changed as they have been asked to leave campuses and adjust to new learning circumstances and adapt on - line learning platforms. Some of these students may have encountered innumerable difficulties with access to computers, laptops and many more and interact at home due to financial disadvantages. With all these rising concerns, the mental wellbeing of students will be significantly affected. Mental health issues can surely out space students' academic success and social interactions could negate their future careers and personal opportunities. This current normal could impair the mental wellbeing of students. 
Based on the results from our gathered data, we concluded that most of the students have WIFI internet connectivity using their mobile phones than their laptops. Slow internet signal was observed and experienced during their online classes. The availability of some alternative gadgets is prominent among the respondents. Therefore, in order to improve our system of education authorities, must look into the provisions of better and stronger WIFI signal and to provide alternative gadget assistance for deprived students of its availability.

\section{References}

Felman, A. (2020, April 14). What is mental health? Medicalnewstoday.com; Medical News Today. https://www.medicalnewstoday.com/articles/154543

What Is Mental Health? | MentalHealth.gov. (2020). Mentalhealth.gov. https://www.mentalhealth.gov/basics/what-is-mental-health

Guadalquiver, N. (2020, May 31). The New Normal in the Philippine Education System. ResearchGate; unknown.

https://www.researchgate.net/publication/344595605_The_New_Normal_in_the_Philippine_Educati on_System

Tria, J. (2020, June 3). The COVID-19 Pandemic through the Lens of Education in the Philippines: The New Normal. ResearchGate; unknown. https://www.researchgate.net/publication/341981898_The_COVID 19_Pandemic_through_the_Len s_of_Education_in_the_Philippines_The_New_Normal

https://plus.google.com/+UNESCO. (2020, October 10). How Do We Protect the Mental Health of Students in a Pandemic. UNESCO. https://en.unesco.org/news/how-do-we-protect mental-healthstudents pandemic\#: :text=If $\% 20 \mathrm{a} \% 20$ student $\% 20$ has $\% 20$ a,indeed $\% 2 \mathrm{C} \% 20$ their $\% 20$ performance $\% 20$ in $\% 20$ school

Chirikov, I., Soria, K. M., Horgos, B., \& Jones-White, D. (2020, August 17). Undergraduate and Graduate Students' Mental Health During the COVID-19 Pandemic. Escholarship.org. https://escholarship.org/uc/item/80k5d5hw

Bonz Magsambol. (2020, October 4). Over 24 million Filipino students back to school during pandemic. Rappler; Rappler. https://www.rappler.com/nation/filipino-students-back-to school-duringcoronavirus-pandemic-october-5-2020

DengBalaga. (2020). Blended Learning: The New Normal. Sti.edu. https://www.sti.edu/sti_news.asp?id=441

The Daily Orange. (2020, October 12). The Daily Orange. http://dailyorange.com/2020/10/online-classescause-mental-health-struggles-students/

The New Normal Education in the Philippines. (2020). Paramountdirect.com. https://www.paramountdirect.com/blogs/the-new-normal-education-in-the-philippines

Stern, J. (n.d.). Introduction to Online Teaching and Learning. http://www.wlac.edu/online/documents/otl.pdf

Dictionary. (2021). Www.dictionary.com. https://www.dictionary.com/browse/new-normal

The world at their fingertips? The mental wellbeing of online distance-based law students. (2019). The Law Teacher. https://www.tandfonline.com/doi/abs/10.1080/03069400.2018.1488910

Aqeel, M., Shuja, K. H., Abbas, J., Rehna, T., \& Ziapour, A. (2020). The Influence of Illness Perception, Anxiety and Depression Disorders on Students Mental Health during COVID 19 Outbreak in Pakistan: A Web-Based Cross-Sectional Survey. https://doi.org/10.21203/rs.3.rs-30128/v1

Crowley, L. (2020, July 8). Adaptation to The New Normal - Practical Challenges \& Tips - Intuition. Intuition. https://www.intuition.com/adaptation-to-the-new-normal-practical challenges-tips/

The Paradigm Shift for Teachers' Challenges in the New Normal - CebuFinest. (2020, October 5). CebuFinest. https://cebufinest.com/paradigm-shift-teachers-challenges-new-normal/

Engagement as a Challenge: Getting Student's Attention in the New Normal of Learning - ADEC Innovations 
Knowledge Management. (2021). Adec-Innovations.com. https://www.km.adecinnovations.com/resources/engagement-as-a-challenge-getting student\%E2\%80\%99s-attention-inthe-new-normal-of-learning/

5 ways to manage student stress | Prospects.ac.uk. (2021). Prospects.ac.uk; Prospects. https://www.prospects.ac.uk/applying-for-university/university-life/5-ways-to-manage studentstress

Fisher, M. (2020, June 25). Recognizing and Coping with Negative Emotions | Called to Care | Johns Hopkins Bayview Medical Center in Baltimore, MD. Hopkinsmedicine.org. https://www.hopkinsmedicine.org/about/community_health/johnshopkins bayview/services/called_to_care/recognize_cope_with_negative_emotions.html

Test your Stress Level with our Free Online Test - 15 Minutes 4 Me. (2012). Miei15Minuti.com. https://www.15minutes4me.com/free-online-test-stress-anxiety-depression burnout/?v=31 